\title{
Transient ionospheric upflow driven by poleward moving auroral forms observed during the Rocket Experiment for Neutral Upwelling 2 (RENU2) campaign
}

\author{
M. Burleigh ${ }^{1,2}$, M. Zettergren ${ }^{2}$, K. Lynch ${ }^{3}$, M. Lessard ${ }^{4}$, J. Moen $^{5,6}$, L. \\ Clausen $^{5}$, D. Kenward ${ }^{4}$, D. Hysell ${ }^{7}$, and M. Liemohn ${ }^{1}$ \\ ${ }^{1}$ University of Michigan \\ ${ }^{2}$ Embry-Riddle Aeronautical University \\ ${ }^{3}$ Dartmouth College \\ ${ }^{4}$ University of New Hampshire \\ ${ }^{5}$ University of Oslo \\ ${ }^{6}$ University Centre in Svalbard \\ ${ }^{7}$ Cornell University
}

Key Points:

- Imager data provides realistic transient forcing constraints for model inputs to simulate observations from a high-latitude rocket flight

- Transient forcing deposits energy over a wider latitudinal region but less energy in any specific location

- Modeling a sequence of poleward moving auroral forms with realistic spatiotemporal variability generates significant latitudinal structuring

This is the author manuscript accepted for publication and has undergone full peer review but has not been through the copyediting, typesetting, pagination and proofreading process, which may lead to differences between this version and the Version of Record. Please cite this article as doi: 10.1029/2018GL081886

Corresponding author: M. Burleigh, mburleig@umich.edu

This article is protected by copyright. All rights reserved. 


\section{8

\begin{abstract}
This study examines cumulative effects of a series of poleward moving auroral forms (PMAFs) on ion upflow and downflow. These effects are investigated using an ionospheric model with inputs derived from the Rocket Experiment for Neutral Upwelling 2 (RENU2) sounding rocket campaign. Auroral precipitation inputs are constrained by all-sky imager brightness values resulting in significant latitudinal structuring in simulated ionospheric upflows due to transient forcing. For contrast, a case with steady forcing, generates almost double the $\mathrm{O}^{+}$upflow transport through $1000 \mathrm{~km}$ when compared to PMAF-like structures. At high altitudes, model results show a spread in upflow response time dependent on ion mass, with molecular ions responding slower than atomic ions by several minutes. While the modeled auroral precipitation is not strong enough to accelerate ions to escape velocities, source populations available for higher-altitude energization processes are greatly impacted by variable forcing exhibited by the RENU2 event.
\end{abstract}

\title{
1 Introduction
}

Heavy ions of ionospheric origin (e.g. $\mathrm{O}^{+}$) are found throughout the terrestrial magnetosphere (see reviews by Welling et al., 2015; Moore \& Horwitz, 2007; Chappell, 1988). The presence of these ions in the magnetosphere results in mass-loading, variations in Alfvén speeds, and alteration of magnetic reconnection rate (e.g. Shay et al., 2004). Such alterations can have significant effects on the global magnetospheric behavior (e.g. Moore \& Delcourt, 1995; Moore et al., 2005). Heavy ions are a significant component of the plasmasheet and ring current plasma, particularly during geomagnetically active times (Young et al., 1982; Kozyra et al., 1987; Gloeckler \& Hamilton, 1987; Hamilton et al., 1988; Orsini et al., 1990; Nosé et al., 2005; Kistler et al., 2005). The cusp region is a prolific source of ionospheric outflow owing to its unique energy inputs (e.g. Varney et al., 2016; Hultqvist et al., 1999). Direct entry of $\sim 100-500 \mathrm{eV}$ electrons results in energy deposition at 200$300 \mathrm{~km}$ altitude where ambient electron temperatures can remain elevated, due to minimal collisional loss to the rarefied neutral atmosphere, and large field-aligned flows can be initiated (Su et al., 1999; Zettergren et al., 2007). These upflows are likely further energized by broadband extremely low frequency (BBELF) waves, also common in the cusp (Strangeway et al., 2005; Kintner et al., 1996)

Poleward moving auroral forms (PMAFs) are quasi-periodic sequences of poleward propagating auroral features, likely associated with pulsed reconnection at the magnetopause (Moen et al., 2004, and references therein). Cusp PMAFs are likely to have a direct impact on ionospheric plasma escape because of the highly transient nature of the associated soft particle precipitation (Su et al., 1999; Moen et al., 2004). Each PMAF may be comprised of smaller sub-arc structures (e.g. Skjaeveland et al., 2011), with spatial extents down to $100 \mathrm{~m}$, that may play some role in variable ionospheric responses. PMAF sequences typically have repetition rate between 2-15 minutes with an average of $\sim 8$ minutes (e.g. Fasel, 1995; Sandholt et al., 1993). Each successive PMAF deposits energy into the local ionosphere, which has been altered to a varying degree by the previous PMAF, resulting, in principle, in a cumulative, complex upflow effect. Because plasma is being extracted (via upflow) from $\sim 250 \mathrm{~km}$ altitudes the response of the ionosphere to successive PMAFs depends in a complicated way on its past time history. Hence, the variable dwell time of PMAFs, coupled with hysteresis, has the potential to create altitude, latitude, and temporal dependence in upflow responses - features that are not wellexplored.

Previous ionospheric modeling studies (e.g. Wu et al., 1999; Burleigh \& Zettergren, 2017) and comparisons against observations (e.g. Sanchez \& Strømme, 2014) have demonstrated that ionospheric sources of plasma to the topside (controlled by low-altitude heating and dynamics) can regulate outward ion fluxes. Most upflow studies examine the "stepresponse" of the ionosphere, by using a fixed precipitation input having some "ramp-up" 
time scale or "on-off" paradigm (e.g. Sadler et al., 2019) - a sensible approach but one that cannot account for situations with complicated time-variable forcing. Few studies have attempted to address the time-dependent forcing effects of a realistically moving source or sequence of sources on upflows (e.g. Zettergren et al., 2014). Global models and single-beam radar experiments do not spatially or temporally resolve important localscale, fast time-scale features associated with ion outflow - e.g. individual discrete arcs (0.5 - $10 \mathrm{~km}$ scales).

Realistic upflow forcing (i.e., source combinations and timing consistent with observations during geophysically significant events) has not been properly characterized via modeling or observations, yet it is clearly of significance to ouflow. Driving models with inputs based on observations (rather than specified in an ad hoc manner) should allow for a more accurate understanding of the duration and location of upflows. This study examines the cumulative spatial and temporal effects of a sequence of PMAFs driving ionospheric field-aligned upflow, downflow, and potentially outflow as observed during the Rocket Experiment for Neutral Upwelling 2 (RENU2) sounding rocket campaign. The primary goal of this study is to assess the effects of realistic transient vs. steady cusptype forcing on low-altitude upflow. This will provide a better understanding of the errors in modeling upflow with poorly resolved energy inputs, and provide realistic expectations for events.

\section{Data Motivating Modeling Efforts}

The RENU2 sounding rocket was launched from the Andøya rocket range on December 13, 2015 at 7:34 UT into the fourth of a series of PMAFs. These PMAFs were observed from $~ 6: 45$ UT onwards through the time of flight, indicating cusp aurora, by the University of Oslo all-sky imager at Longyearbyen (LYR) (data can be found at http:// tid.uio.no/plasma/aurora/). In general, the PMAFs exhibited northward movement with a speed of $\sim 1 \mathrm{~km} / \mathrm{s}$ and latitudinal width of $\sim 0.6^{\circ}$ (as discerned from redline imager data, Figure 1a). Each PMAF displays unique deviations from this general pattern.

RENU2 in situ electron precipitation measurements in Figure 1b show passage through the cusp in the latter part of the flight (7:41:20 UT onwards) - characterized by soft $(<$ $300 \mathrm{eV}$ ) particle precipitation, which will deposit energy at $\geq 200 \mathrm{~km}$ altitude, exciting strong $630 \mathrm{~nm}$ emission (panel a) and heating the ambient ionospheric electrons. ERPA data (Frederick-Frost et al., 2007) from RENU2 are shown in Figure 1c and illustrate a clear correlation between elevated electron temperatures and the softer particle precipitation. DC electric field measurements from the COWBOY instrument (Lundberg, Kintner, Powell, \& Lynch, 2012; Lundberg, Kintner, Lynch, \& Mella, 2012, and references therein), Figure 1d, are small but show an enhancement just equatorward of the cusp/PMAF. These measurements, when compared to the speed of this PMAF, suggest that the PMAF was not locked into the slower background convection; a somewhat unusual situation (e.g. Kozlovsky \& Kangas, 2002). A more comprehensive description and analysis of the data summarized in Figure 1 is given in Lessard et al. (2019). Here we focus on only the basic features necessary to set up a modeling study of transient behavior. Collectively, the information shown in Figure 1a, b, and d, are used as inputs to drive the Geospace Environment Model of Ion-Neutral Interactions with Transverse Ion Acceleration (GEMINI-TIA) ionospheric model.

\section{Ionospheric Model}

GEMINI-TIA (described in detail in Burleigh \& Zettergren (2017)) is the 2D, multifluid, ionospheric model used for this study. GEMINI-TIA solves the nonlinear equations for conservation of mass, momentum, parallel energy, and perpendicular energy for six ion species relevant to the $E$ and $F$ regions and topside ionosphere $\left(\mathrm{O}^{+}, \mathrm{NO}^{+}, \mathrm{N}_{2}^{+}, \mathrm{O}_{2}^{+}\right.$, $\mathrm{N}^{+}$, and $\mathrm{H}^{+}$). This fluid description is coupled to a quasi-static solution for auroral and 

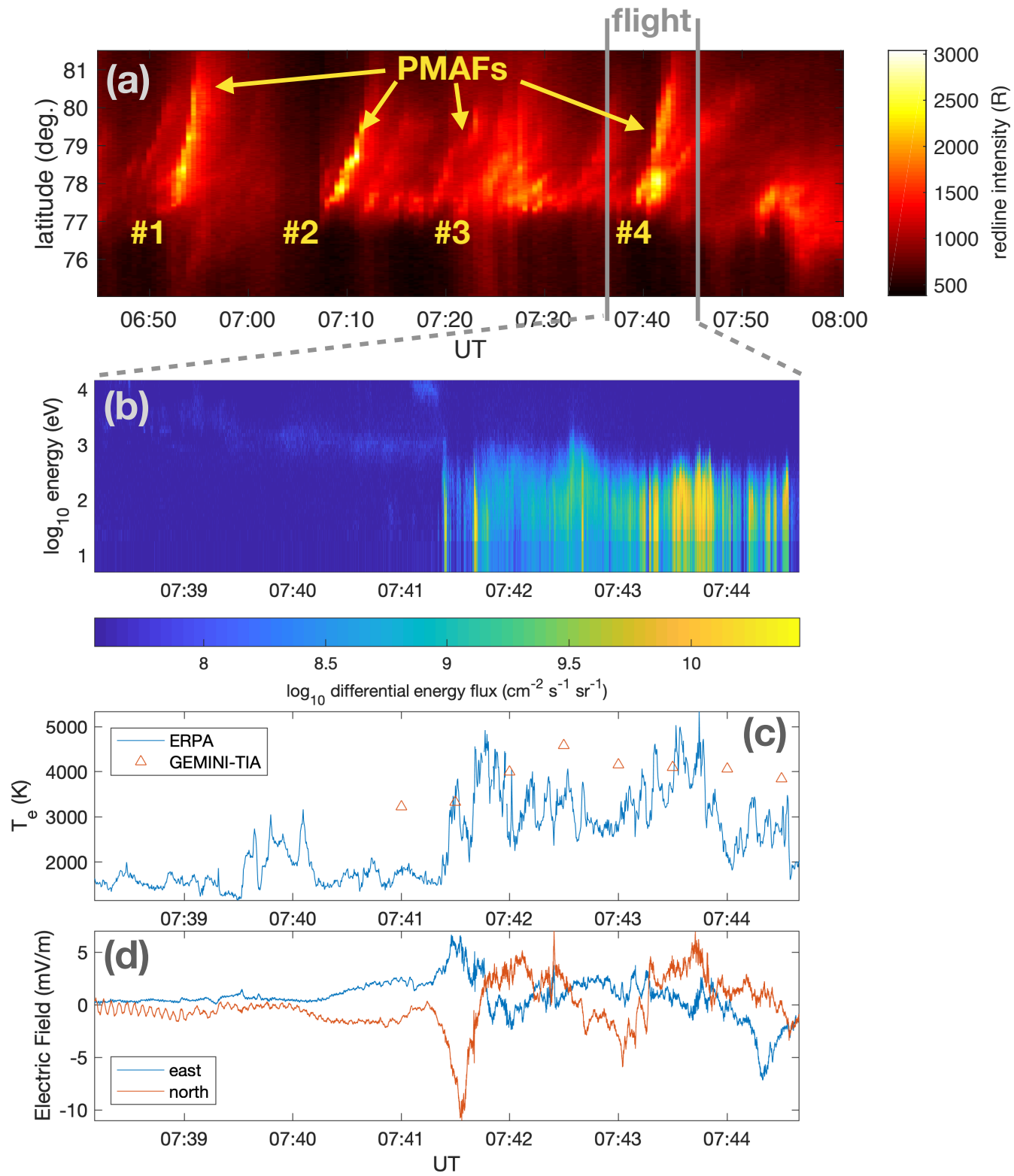

Figure 1. Normalized, along-trajectory brightness measurements from the imager at LYR (panel a), in situ precipitation measurements in the form of characteristic energy and total energy flux (panel b) and the in situ DC electric field (panel d) are processed and used as model inputs. The in situ electron temperature measurements (panel c) can be compared to model results. 
neutral dynamo electric currents. GEMINI-TIA includes the effects of precipitating electrons on the ambient ionospheric plasma, including ionization and thermal electron heating - necessary to capture $F$ region and topside upflow. GEMINI-TIA further includes a parameterization of transverse heating by BBELF waves and parallel ion inertial effects necessary for simulating high-speed plasma upflows.

Inputs for GEMINI-TIA include topside ionospheric potential, electron precipitation, power spectral density from BBELF waves, and neutral winds (Burleigh et al., 2018). For this study, GEMINI-TIA is initialized only with data-inspired precipitation and DC electric field values to mimic the effects of the observed PMAFs. The model utilizes a non-uniform tilted-dipole grid (Huba et al., 2000) with a resolution of $\sim 4 \times 12 \mathrm{~km}$ (horizontal $\times$ vertical) in the $E$ region and increases to a resolution of $\sim 6 \times 15 \mathrm{~km}$ in the topside. The grid's geophysical location is set to encompass the rocket trajectory. The model uses an adaptive time step to ensure stability, typically $\sim 1.4 \mathrm{~s}$ for this type of grid.

In situ particle precipitation and DC electric field measurements (Figure 1b and $\mathrm{d}$, respectively) are used as reference for selecting representative input values for the model. Specifically, a northward DC electric field of $8 \mathrm{mV} / \mathrm{m}$, a total energy flux of $0.75 \mathrm{~mW} / \mathrm{m}^{2}$, and a characteristic energy of $100 \mathrm{eV}$ are used as the energy inputs driving the model. For each time step, the brightness measurement from the ground based all-sky imager at Longyearbyen (LYN) was smoothed using a Gaussian-weighted moving average with a fixed window length of 50 points to retain the fundamental shape of the PMAFs in the keogram while suppressing measurement noise. The total energy flux and the DC electric field are multiplied by the normalized, and smoothed, brightness measurements (Figure 3a) to control where, when, and at what relative strength the aurora is modeled. The data are then linearly interpolated over time to increase the temporal resolution from a 30 second cadence to a 5 second cadence to facilitate model use. Preserving the unique and detailed energy signature for each PMAF is beyond the scope of this paper but may be a future focus. The brightness weighted, constant energy drivers are implemented to allow for the impacts of the variability of the PMAF sequence to be the focus of this study.

To illustrate the impact of background convection, a second simulation has been run that uses the same inputs above and a brightness weighted eastward DC electric field of $50 \mathrm{mV} / \mathrm{m}$. This generates a local background convection approximately equivalent to the PMAF speed $(\sim 1 \mathrm{~km} / \mathrm{s})$. We also run a third simulation assuming steady forcing, to contrast with the runs with transient forcing. This third simulation uses total energy flux $\left(0.75 \mathrm{~mW} / \mathrm{m}^{2}\right)$ and characteristic energy $(100 \mathrm{eV})$ which are applied constantly for 20 minutes using a latitudinal Gaussian envelope, centered on $\sim 77^{\circ}$, with a half-width of $\sim 0.6^{\circ}$ to create latitudinal structure.

\section{Ionospheric Response to a Sequence of PMAFs}

\subsection{Transient vs. Steady Forcing}

Three simulations to study transient vs. steady cusp-type forcing on low-altitude upflow are presented in this section. Cusp auroral precipitation increases electron densities and temperatures, hence pressure, throughout the $F$ region and topside ionosphere. The electron pressure increase results in a stronger ambipolar electric field which enhances the upward field-aligned flow of plasma (Su et al., 1999). The electron temperature, $\mathrm{O}^{+}$ field-aligned velocity, and $\mathrm{O}^{+}$flux from 6:45 to 7:05 UT are shown in Figure 2 for each simulation (Transient Forcing - PMAF \#1 vs. Steady Forcing vs. Fast Convection).

The $100 \mathrm{eV}$ soft precipitation, within the steady forcing simulation, quickly elevates electron temperatures from $\sim 2000 \mathrm{~K}$ to $6000 \mathrm{~K}$ (Figure $2 \mathrm{~b}$ ) at $76^{\circ}$ and, through auroral ionization, creates more $F$ region $\mathrm{O}^{+}$. As local ion densities increase, the energy deposited into the $F$ region from the auroral precipitation is distributed amongst/acts on an increasing ion population resulting in slightly less apparent electron heating as the 


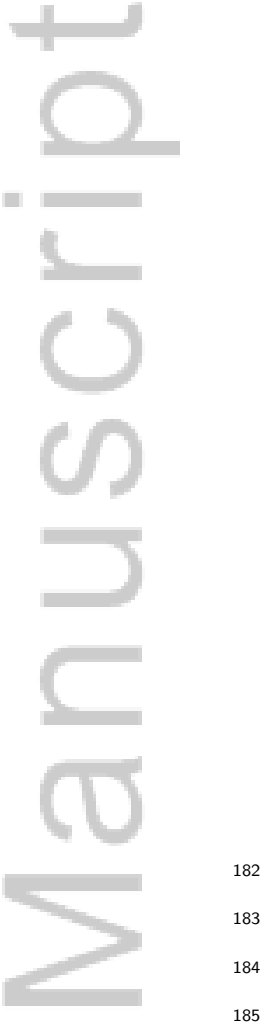

185
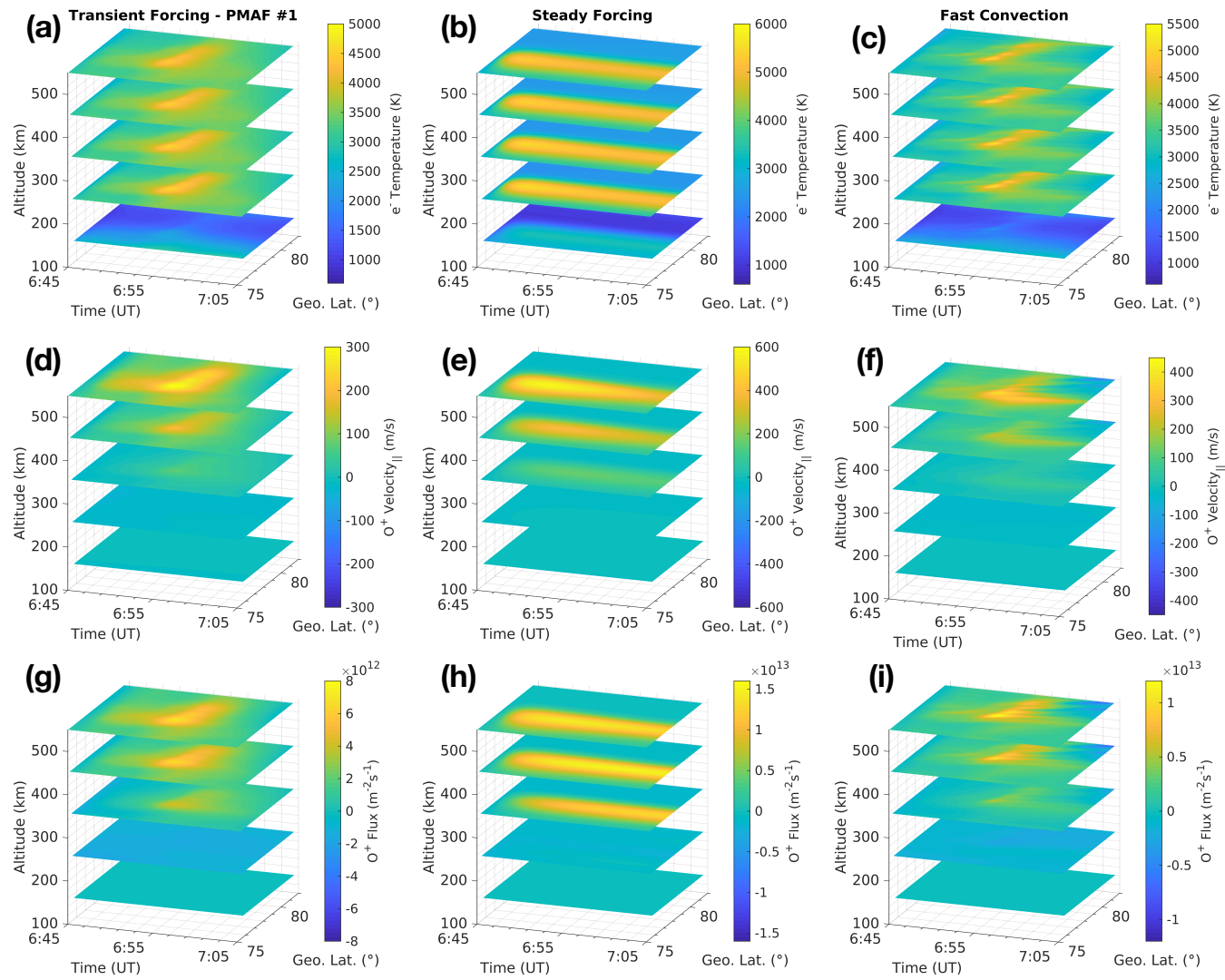
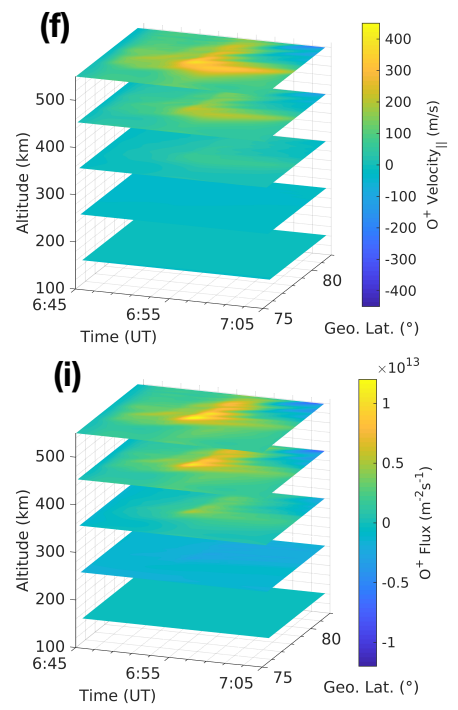

Figure 2. From the top down, the electron temperature, $\mathrm{O}^{+}$field aligned velocity, and the $\mathrm{O}^{+}$flux at five altitudinal slices $(150,250,350,450,550 \mathrm{~km})$ from 6:45 to 7:05 UT for the realistic transient forcing (left column), steady forcing (center column), and fast convection (right column) simulations. Note: Colorbar ranges are not identical.

event proceeds. The $\mathrm{O}^{+}$velocity in the topside is driven to $>600 \mathrm{~m} / \mathrm{s}$ within $\sim 2$ minutes and then tapers off as more material is pushed upwards, counteracting the initial pressure gradient (panel e). The $\mathrm{O}^{+}$flux during this simulation remains mostly constant due to the fact that there are more ions at higher altitudes which approximately counterbalances the decrease in drift speed with time as the event progresses (panel h).

For comparison, the transient forcing simulation utilizes just the first PMAF (\#1) that occurred during the same time window (6:45-7:05 UT) (see Figure 1a). The PMAF dwells in the same latitudinal region $\left(\sim 78^{\circ}\right)$, increasing the local ionospheric response (i.e. greater ion fluxes, stronger field aligned ion velocities, and larger temperatures), until 6:50 UT when there is brightening/northward elongation and motion. The motion northward then results in a relatively smaller amount of energy (as compared to the steady forcing simulation) being deposited in any localized region. The normalized-brightness data provides a realistic spatiotemporal variability in the energy input location and strength, as seen in the structured response in Figure 2a, d, and g. Increasing the background convection to be roughly equivalent to the PMAF speed results in a stronger structured response (Figure 2c, f, and i) from the local plasma staying within the moving energization region longer and additional frictional heating.

The steady cusp-type forcing generates an $\mathrm{O}^{+}$response almost twice the intensity of the realistic transient forcing. Integrating the flux over time and space, the total num- 
ber of $\mathrm{O}^{+}$ions transported by the steady cusp-type forcing is $3.3 \times 10^{16}$ at $1000 \mathrm{~km}$ over the course of the simulation. By comparison, the transient forcing - PMAF \#1 simulation has a total transport of $1.9 \times 10^{16} \mathrm{O}^{+}$ions at $1000 \mathrm{~km}$ and the fast convection simulation generates $3.0 \times 10^{16}$ ions at $1000 \mathrm{~km}$. While the northward propagation of the PMAF allows for more spatial area to be energized, the total amount of energy input into a given area can be less. Using constant forcing, or a long duration "on-off" mechanism, to represent PMAFs, has the potential to severely over-estimate ionospheric responses.

\subsection{Effects of a Sequence of PMAFs}

Using the full observed PMAF sequence (6:45 to 8:00 UT) generates a structured ion response in the model. The first PMAF from 6:47 to 7:04, sweeps poleward through the local ionosphere and lofts ions upwards. The first PMAF to pass through the region generates the strongest flows. There are only a few minutes of "rest time" between the first and second PMAF for the ionosphere to relax back towards a quiescent state and begin to downflow (this is relatively short compared to the time required to establish a relatively steady ion upflow response (e.g. Burleigh \& Zettergren, 2017)). The second PMAF, from 7:07 to 7:18 UT, deposits energy at approximately the same latitudes as the first PMAF which increases $\mathrm{O}^{+}$densities at higher altitudes, as shown in Figure 3d. The third PMAF, from $~ 7: 18$ to 7:38 UT is not as strong but has a longer duration. The fourth PMAF, from 7:38 to 7:51 UT, is the PMAF the rocket flew through. The cumulative effects of this series of PMAFs can be seen in the large increase in $\mathrm{O}^{+}$densities at even higher altitudes (panel e).

PMAF motions, and changes in intensity, generate periods of significant latitudinal differences in the ionospheric state. For example, during the second PMAF at 7:11 UT, auroral precipitation increases electron temperatures and drives upflow between $\sim 77$ $78^{\circ}$ (Figure $3 \mathrm{f}$ and h respectively). In contrast, the northernmost modeled latitudes $\left(>79^{\circ}\right)$ at this time have not been re-visited by auroral activity and show downflow (panel h). PMAF dwell time in a latitudinal region determines the amount of ion flux generated (panel j).

Only local, medium scale downflows are generated in this simulation. Smaller subarc (spatial) scale downflows are often observed by sounding rockets (Lynch et al., 2007; Fernandes et al., 2016). These sub-arc scale structures are not captured here potentially due to the structure size being below the resolution of the simulation or smoothing applied to model inputs removed fine scale details responsible for driving the downflows. However, this simulation does illustrate a scenario under which downflows occur, i.e. strong forcing at local spatial and temporal scales.

As an additional example of the dynamic response to PMAF motions, latitudes $>79^{\circ}$ that previously contained downflow after PMAF \#1, show upflow (panel i) at 7:43:30, as PMAF \#4 (panel c) passes through the region. The latitudinal extent of the PMAF motion has elevated electron temperatures over a broad region (panel $\mathrm{g}$ ). Effects of time history are evident as a stronger part of the PMAF has just passed through the region (see the brighter region just to the left of the second magenta line in Figure 3a) resulting in, cumulatively, more $\mathrm{O}^{+}$lofted to higher altitudes (panel e). The ion flux at this time is larger as well (panel k).

When the RENU2 sounding rocket (Figure 3c, cyan star) is within the fourth PMAF the electron temperatures (Figure 1c, blue line) fluctuate between 2500 and $5000 \mathrm{~K}$ from $\sim 7: 41: 20$ to $\sim 7: 44: 00$. The modeled electron temperatures, at the rocket's location, fall within this range (Figure 1c, orange triangles) and provide a point of verification for this method of modeling PMAFs.

The variable dwell time of PMAFs at a latitudinal region impacts the ion flux generated there at high altitudes. At $1000 \mathrm{~km}$, the upflow takes $\sim 7$ minutes to reach this 

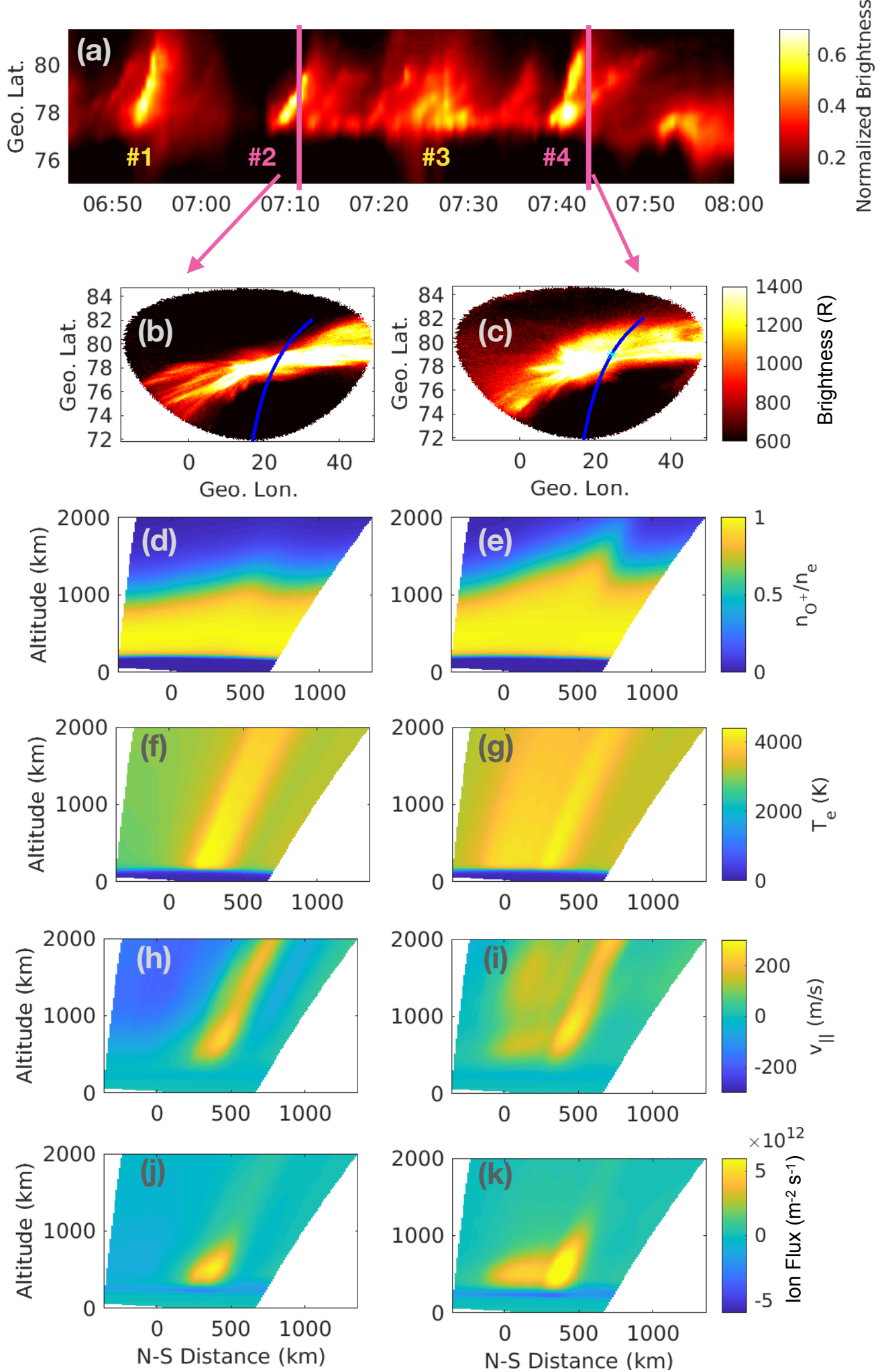

Figure 3. Modeled ionospheric parameters from PMAF \#2 at 7:11:00 (left column) and PMAF \#4 at 7:43:30 UT (right column). These times are indicated by the magenta vertical lines in panel a. The all-sky imager brightness (panels b and c) are overlaid with the rocket trajectory (and keogram trace line) in blue. The model uses a tilted-dipole grid as seen in panels d-k. 

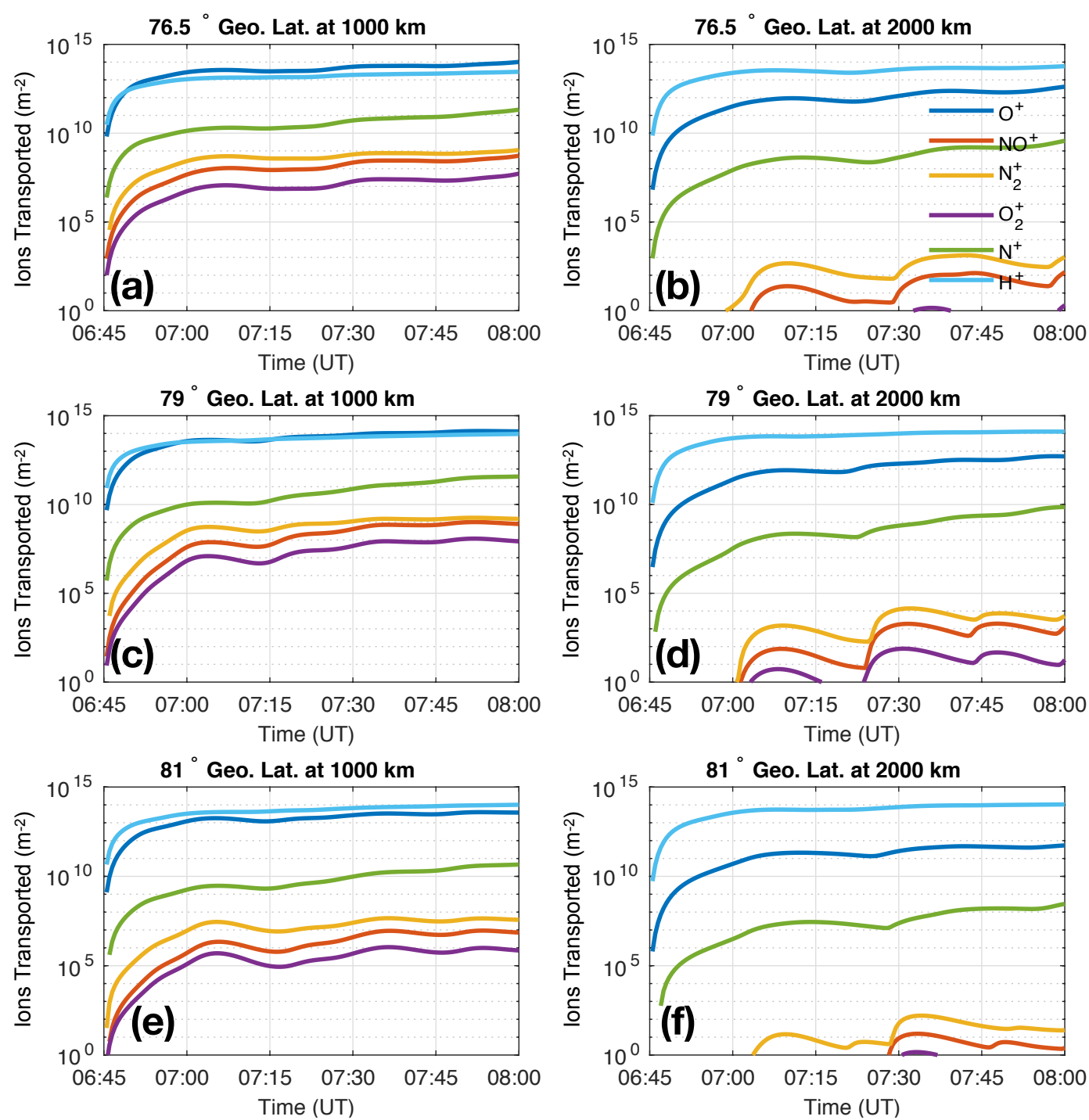

Figure 4. Cumulative number of particles per unit area (transport) for each ion specie passing through $1000 \mathrm{~km}$ and $2000 \mathrm{~km}$ at three separate latitudes. The results from a control simulation, without any PMAFs (i.e. including only ambient transport effects), have been subtracted to highlight PMAF driven transport. 
altitude (difference in time between the end of the brightness of the PMAF and the corresponding peak in transport at this altitude in Figure 4). At $2000 \mathrm{~km}$, it takes $\sim 11$ minutes for ion upflow to reach this altitude. Increasing transport over time is due to upflow and decreasing transport is due to downflow. At $76.5^{\circ}$, PMAFs 1 and 3 have the greatest impact on the transport; PMAFs 2 and 4 do not provide significant precipitation this far south. This is seen in the two peaks in transport at both 1000 and $2000 \mathrm{~km}$ in Figure $4 \mathrm{a}$ and b. At $79^{\circ}$ (panels c and d) and $81^{\circ}$ (panels e and $\mathrm{f}$ ), all four PMAFs influence this region (minimal influence from PMAF 2 at $81^{\circ}$ ). The dwell time of PMAF activity around $81^{\circ}$ is shorter than at $79^{\circ}$ so less material reaches $2000 \mathrm{~km}$.

There is a transport response time difference between the ion species at these altitudes. For example, the first peak in transport at $1000 \mathrm{~km}$, at $81^{\circ}$ (Figure 4e), is reached by $\mathrm{O}^{+}$at 7:05:00, $\mathrm{N}^{+}$at 7:05:30, $\mathrm{NO}^{+}$at 7:06:00, $\mathrm{N}_{2}^{+}$at 7:05:30, and $\mathrm{O}_{2}^{+}$at 7:05:30; a minute spread in response time. $\mathrm{H}^{+}$at this altitude and latitude does not have a distinct peak for comparison; the transport continues to increase over time. The response time differences become more pronounced by the second PMAF, which is from $\sim 7: 07$ to 7:18 UT. The species dependent delay at which the ion species changes from downflowing to upflowing is at 7:14:00 for $\mathrm{O}^{+}, 7: 14: 00$ for $\mathrm{N}^{+}, 7: 16: 00$ for $\mathrm{NO}^{+}, 7: 16: 30$ for $\mathrm{N}_{2}^{+}$, and 7:16:30 for $\mathrm{O}_{2}^{+}$for this PMAF. The overall transition from downflow to upflow for all ion species occurs over a period of 2 minutes and 30 seconds.

\section{Conclusions and Future Work}

In this study we demonstrate a data-representative (as opposed to data-driven) modeling approach to incorporate brightness from all-sky imagers as a constraint for auroral ionospheric model inputs. This method allows for realistic forcing that is not captured with a traditional "on-off" descriptions of PMAFs. There is agreement between the electron temperatures measured in situ by the rocket and the modeled electron temperatures along the rocket trajectory during PMAF \#4 when the rocket was in flight (see Figure 1c) indicating that this method works well for local-scale features.

Comparing the steady forcing simulation to PMAF \#1, the basic physical processes in play are the same; auroral precipitation elevates electron densities and temperatures resulting in an enhanced ambipolar electric field which drives ion upflow. The steady forcing simulation shows upflow confined to latitudes $\left(\sim 75-78^{\circ}\right)$ where the energy inputs associated with auroral precipitation are largest. The PMAF simulation, on the other hand, shows large latitudinal and temporal variation of ion upflow and electron temperature. The total $\mathrm{O}^{+}$transported through $1000 \mathrm{~km}$, due to the steady forcing, is approximately twice that generated by PMAF \#1, which generated the strongest upflows from the PMAF sequence and still $10 \%$ greater than the fast convection simulation.

Using the full PMAF sequence generates significant spatiotemporal variation of fieldaligned ion velocities and fluxes within the model. The variable dwell time of the PMAFs in any given latitudinal region impacts the ion flux generated there at high altitudes. For example, not all PMAFs had the same latitudinal extent, two did not reach as far south as $76.5^{\circ}$ so that latitudinal region received less energy. The dwell time of each PMAF at higher latitudes, for example at $81^{\circ}$, is shorter than at $79^{\circ}$ so less ionospheric material is driven to $2000 \mathrm{~km}$. There is also an ion species dependence in the response time where the heavier molecular ions are slower to respond. By the second PMAF, there is a 2 minute 30 second spread in response as downflows are driven to upflows.

While soft electron precipitation is itself insufficient to accelerate ions to escape velocities, source populations available for higher-altitude energization processes are greatly increased. Plans for future work include a characterization of transverse energization effects. The transient nature of PMAFs may affect the conversion of upflow to outflow via BBELF transverse ion acceleration. 


\section{Acknowledgments}

MB was supported by NSF CAREER grant AGS-1255181 and NASA grant 80NSSC17K0015, MZ by NSF CAREER grant AGS-1255181, and ML by NASA grant 80NSSC17K0015. Support was provided at the University of New Hampshire by NASA award NNX13AJ94G, at Dartmouth College by NASA award NNX13AJ90G, and at Cornell University by NASA award NNX13AJ91G. JM received funding from the Research Council of Norway grant 275653 .

RENU2 data are available at NASA's Space Physics Data Facility (SPDF, spdf .gsfc.nasa.gov). University of Oslo all-sky imager data are available at http://tid .uio.no/plasma/aurora. Model results (doi:10.7302/pcrt-dj64) are archived in Deep Blue Data (https://deepblue.lib.umich.edu/data).

\section{References}

Burleigh, M. R., Heale, C. J., Zettergren, M. D., \& Snively, J. B. (2018). Modulation of low-altitude ionospheric upflow by linear and nonlinear atmospheric gravity waves. Journal of Geophysical Research: Space Physics, 123(9), 7650-7667. doi: 10.1029/2018JA025721

Burleigh, M. R., \& Zettergren, M. D. (2017). Anisotropic fluid modeling of ionospheric upflow: Effects of low-altitude anisotropy and thermospheric winds. Journal of Geophysical Research: Space Physics. doi: 10.1002/2016JA023329

Chappell, C. R. (1988). The terrestrial plasma source: A new perspective in solarterrestrial processes from dynamics explorer. Reviews of Geophysics, 26 (2), 229248. doi: $10.1029 /$ RG026i002p00229

Fasel, G. J. (1995). Dayside poleward moving auroral forms: A statistical study. Journal of Geophysical Research: Space Physics, $100(\mathrm{~A} 7), 11891-11905 . \quad$ doi: 10 .1029/95JA00854

Fernandes, P. A., Lynch, K. A., Zettergren, M., Hampton, D. L., Bekkeng, T. A., Cohen, I. J., ... Powell, S. P. (2016). Measuring the seeds of ion outflow: Auroral sounding rocket observations of low-altitude ion heating and circulation. Journal of Geophysical Research: Space Physics, 121(2), 1587-1607. doi: 10.1002/2015JA021536

Frederick-Frost, K. M., Lynch, K. A., Kintner, P. M., Klatt, E., Lorentzen, D., Moen, J., ... Widholm, M. (2007). Sersio: Svalbard eiscat rocket study of ion outflows. J. Geophys. Res., 112.

Gloeckler, G., \& Hamilton, D. C. (1987). Ampte ion composition results. Physica Scripta, 1987(T18), 73. doi: 10.1088/0031-8949/1987/T18/009

Hamilton, D. C., Gloeckler, G., Ipavich, F. M., Stdemann, W., Wilken, B., \& Kremser, G. (1988). Ring current development during the great geomagnetic storm of february 1986. Journal of Geophysical Research: Space Physics, 93(A12), 14343-14355. doi: 10.1029/JA093iA12p14343

Huba, J. D., Joyce, G., \& Fedder, J. A. (2000). Sami2 is another model of the ionosphere (sami2): A new low-latitude ionosphere model. Journal of Geophysical Research: Space Physics, 105(A10). doi: 10.1029/2000JA000035

Hultqvist, B., Øieroset, M., Paschmann, G., \& Treumann, R. (1999). Magnetospheric plasma sources and losses. Space Sci. Rev., 88.

Kintner, P. M., Bonnell, J., Arnoldy, R., Lynch, K., Pollock, C., \& Moore, T. (1996). SCIFER-Transverse ion acceleration and plasma waves. Geophys. Res. Lett., 23, 1873-1876.

Kistler, L. M., Mouikis, C., Mbius, E., Klecker, B., Sauvaud, J. A., Rme, H., ... Balogh, A. (2005). Contribution of nonadiabatic ions to the cross-tail current in an o+ dominated thin current sheet. Journal of Geophysical Research: Space Physics, 110(A6). doi: 10.1029/2004JA010653 
Kozlovsky, A., \& Kangas, J. (2002). Motion and origin of noon high-latitude poleward moving auroral arcs on closed magnetic field lines. Journal of Geophysical Research: Space Physics, 107(A2). doi: 10.1029/2001JA900145

Kozyra, J. U., Shelley, E. G., Comfort, R. H., Brace, L. H., Cravens, T. E., \& Nagy, A. F. (1987). The role of ring current o+ in the formation of stable auroral red arcs. Journal of Geophysical Research: Space Physics, 92(A7), 7487-7502. doi: 10.1029/JA092iA07p07487

Lessard, M. R., F., B., S., B., Cohen, I., D. Kenward, N. G., Clemmons, J. H., ... Yeoman, T. (2019). Overview of the Rocket Experiment for Neutral Upwelling Sounding Rocket 2 (RENU2). Geophys. Res. Lett.. (submitted)

Lundberg, E. T., Kintner, P. M., Lynch, K. A., \& Mella, M. R. (2012). Multipayload measurement of transverse velocity shears in the topside ionosphere (Vol. 39). doi: 10.1029/2011GL050018

Lundberg, E. T., Kintner, P. M., Powell, S. P., \& Lynch, K. A. $\quad$ (2012). Multipayload interferometric wave vector determination of auroral hiss (Vol. 117). doi: 10.1029/2011JA017037

Lynch, K. A., Semeter, J. L., Zettergren, M., \& Kinter, P. (2007). Auroral ion outflow: Low altitude energization. Ann. Geophys., 25.

Moen, J., Oksavik, K., \& Carlson, H. C. (2004). On the relationship between ion upflow events and cusp auroral transients. Geophys. Res. Lett., 31, 11808.

Moore, T. E., \& Delcourt, D. C. (1995). The geopause. Reviews of Geophysics, 33(2), 175-209. doi: 10.1029/95RG00872

Moore, T. E., Fok, M.-C., Chandler, M. O., Chappell, C. R., Christon, S. P., Delcourt, D. C., ... Slinker, S. (2005). Plasma sheet and (nonstorm) ring current formation from solar and polar wind sources. Journal of Geophysical Research: Space Physics, 110(A2).

Moore, T. E., \& Horwitz, J. L. (2007). Stellar ablation of planetary atmospheres. Reviews of Geophysics, 45, 1944-9208.

Nosé, M., Taguchi, S., Hosokawa, K., Christon, S., McEntire, R., Moore, T., \& Collier, M. (2005). Overwhelming o+ contribution to the plasma sheet energy density during the october 2003 superstorm: Geotail/epic and image/lena observations. Journal of Geophysical Research: Space Physics, 110(A9).

Orsini, S., Candidi, M., Stokholm, M., \& Balsiger, H. (1990). Injection of ionospheric ions into the plasma sheet. Journal of Geophysical Research: Space Physics, 95(A6), 7915-7928. doi: 10.1029/JA095iA06p07915

Sadler, F. B., Lessard, M., \& Otto, A. (2019). Efects of periodic precipitation on ion upflow and neutral upwelling. Geophys. Res. Lett.. (submitted)

Sanchez, E. R., \& Strømme, A. (2014). Incoherent scatter radar-fast satellite common volume observations of upflow-to-outflow conversion. Journal of Geophysical Research: Space Physics, 119(4), 2649-2674. doi: 10.1002/2013JA019096

Sandholt, P., Moen, J., Opsvik, D., Denig, W., \& Burke, W. (1993). Auroral event sequence at the dayside polar cap boundary: Signature of time-varying solar windmagnetosphere-ionosphere coupling. Advances in Space Research, 13(4), 7 - 15. doi: https://doi.org/10.1016/0273-1177(93)90305-U

Shay, M. A., Drake, J. F., Swisdak, M., \& Rogers, B. N. (2004, May). The scaling of embedded collisionless reconnection. Physics of Plasmas, 11, 2199-2213. doi: 10 $.1063 / 1.1705650$

Skjaeveland, A., Moen, J., \& Carlson, H. C. (2011). On the relationship between flux transfer events, temperature enhancements, and ion upflow events in the cusp ionosphere. Journal of Geophysical Research: Space Physics, 116(A10).

Strangeway, R. J., Ergun, R. E., Su, Y. J., Carlson, C. W., \& Elphic, R. C. (2005). Factors controlling ionospheric outflows as observed at intermediate altitudes. $J$. Geophys. Res., 110.

Su, Y., Caton, R., Horwitz, J., \& Richards, P. (1999). Systematic modeling of 
soft-electron precipitation effects on high-latitude $\mathrm{f}$ region and topside ionospheric upflows. Journal of geophysical research, 104, 153-163.

Varney, R. H., Wiltberger, M., Zhang, B., Lotko, W., \& Lyon, J. (2016). Influence of ion outflow in coupled geospace simulations: 1. physics-based ion outflow model development and sensitivity study. Journal of Geophysical Research: Space Physics, 121(10), 9671-9687. doi: 10.1002/2016JA022777

Welling, D., André, M., Dandouras, I., Delcourt, D., Fazakerley, A., Fontaine, D., ... Yau, A. (2015). The earth: Plasma sources, losses, and transport processes. Space Science Reviews, 192(1-4), 145-208.

Wu, X.-Y., Horwitz, J. L., Estep, G. M., Su, Y.-J., Brown, D. G., Richards, P. G., \& Wilson, G. R. (1999). Dynamic fluid-kinetic (dyfk) modeling of auroral plasma outflow driven by soft electron precipitation and transverse ion heating. Journal of Geophysical Research: Space Physics, 104(A8), 17263-17275. doi: 10.1029/1999JA900114

Young, D. T., Balsiger, H., \& Geiss, J. (1982). Correlations of magnetospheric ion composition with geomagnetic and solar activity. Journal of Geophysical Research: Space Physics, 87(A11), 9077-9096. doi: 10.1029/JA087iA11p09077

Zettergren, M., Lynch, K., Hampton, D., Nicolls, M., Wright, B., Conde, M., ... Powell, S. (2014). Auroral ionospheric f region density cavity formation and evolution: Mica campaign results. Journal of Geophysical Research: Space Physics, 119(4), 3162-3178. doi: 10.1002/2013JA019583

Zettergren, M., Semeter, J., Blelly, P. L., \& Diaz, M. (2007). Optical estimation of auroral ion upflow: Theory. J. Geophys. Res., 112. 


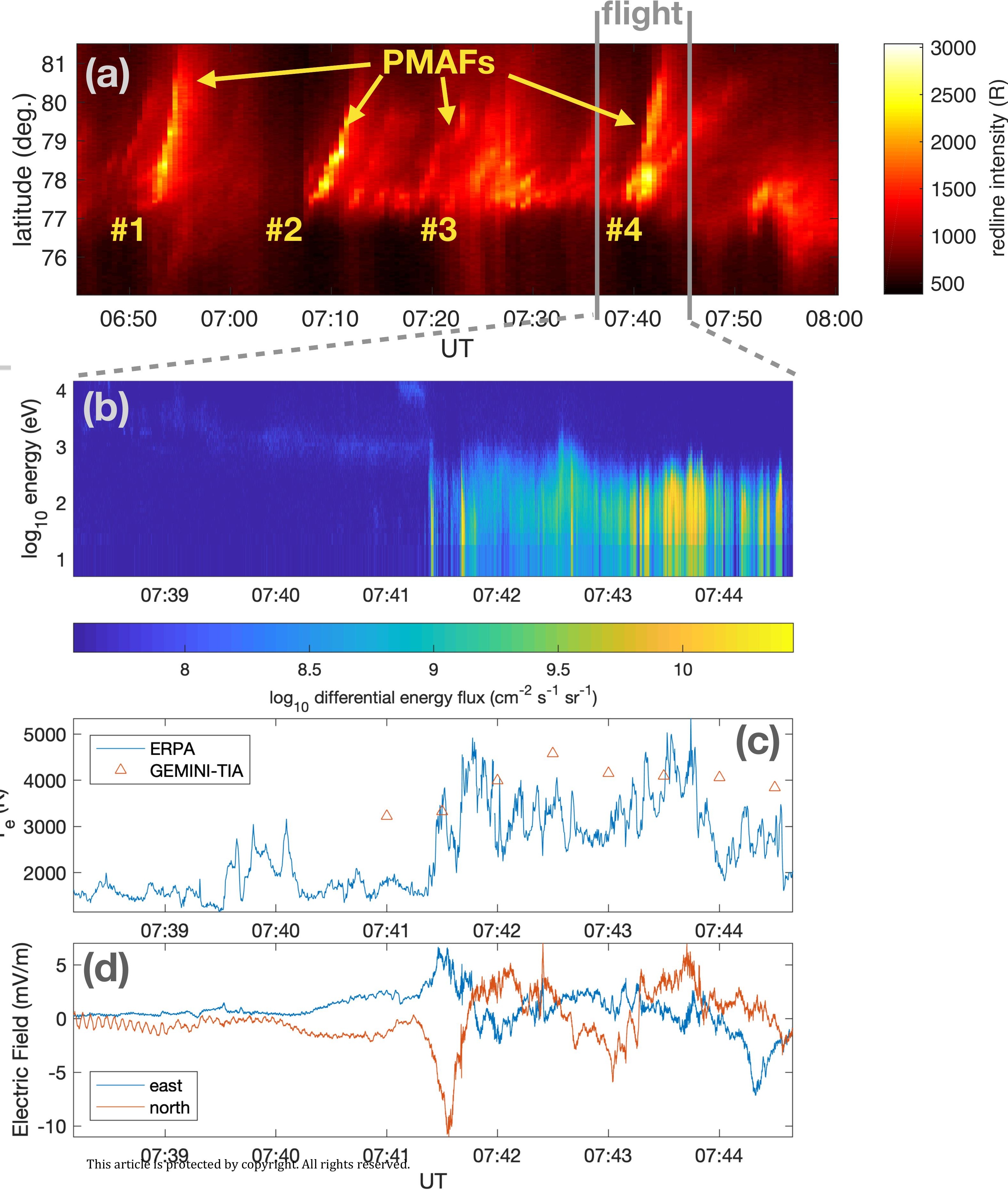


Figure 2.
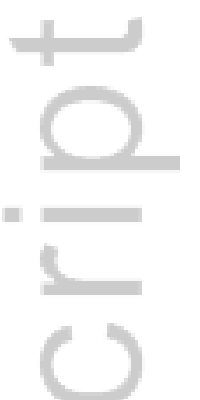

$\infty$
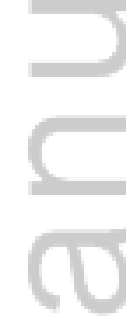

This article is protected by copyright. All rights reserved. 

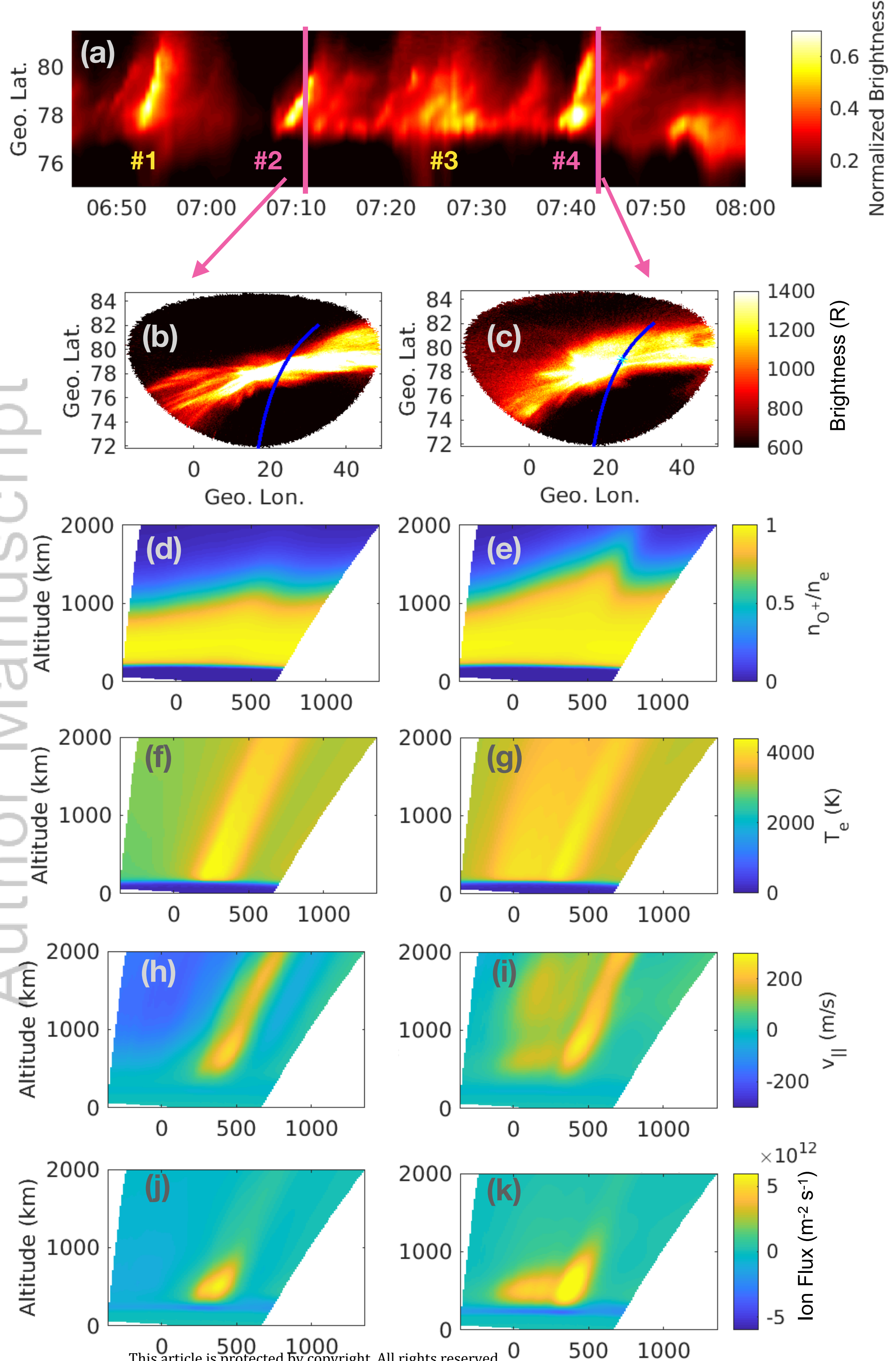

This article is protected by copyright. All rights reserved. $0 \quad 500 \quad 1000$ N-S Distance (km) N-S Distance $(\mathrm{km})$ 

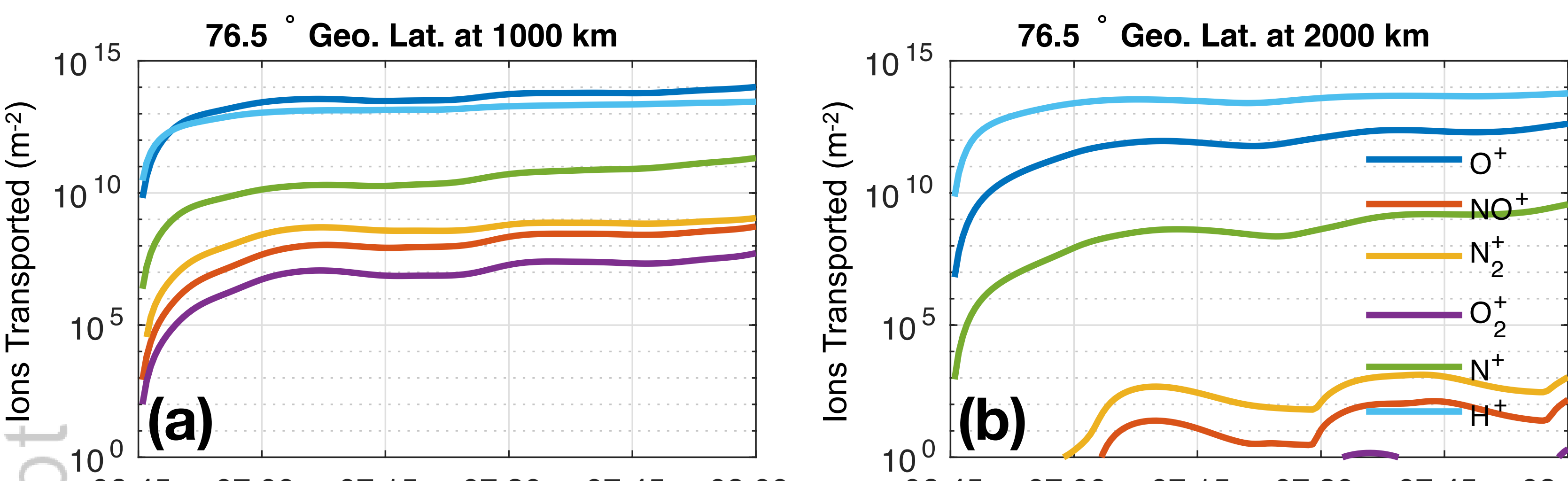

$\begin{array}{llllll}06: 45 & 07: 00 & 07: 15 & 07: 30 & 07: 45 & 08: 00\end{array}$ Time (UT)

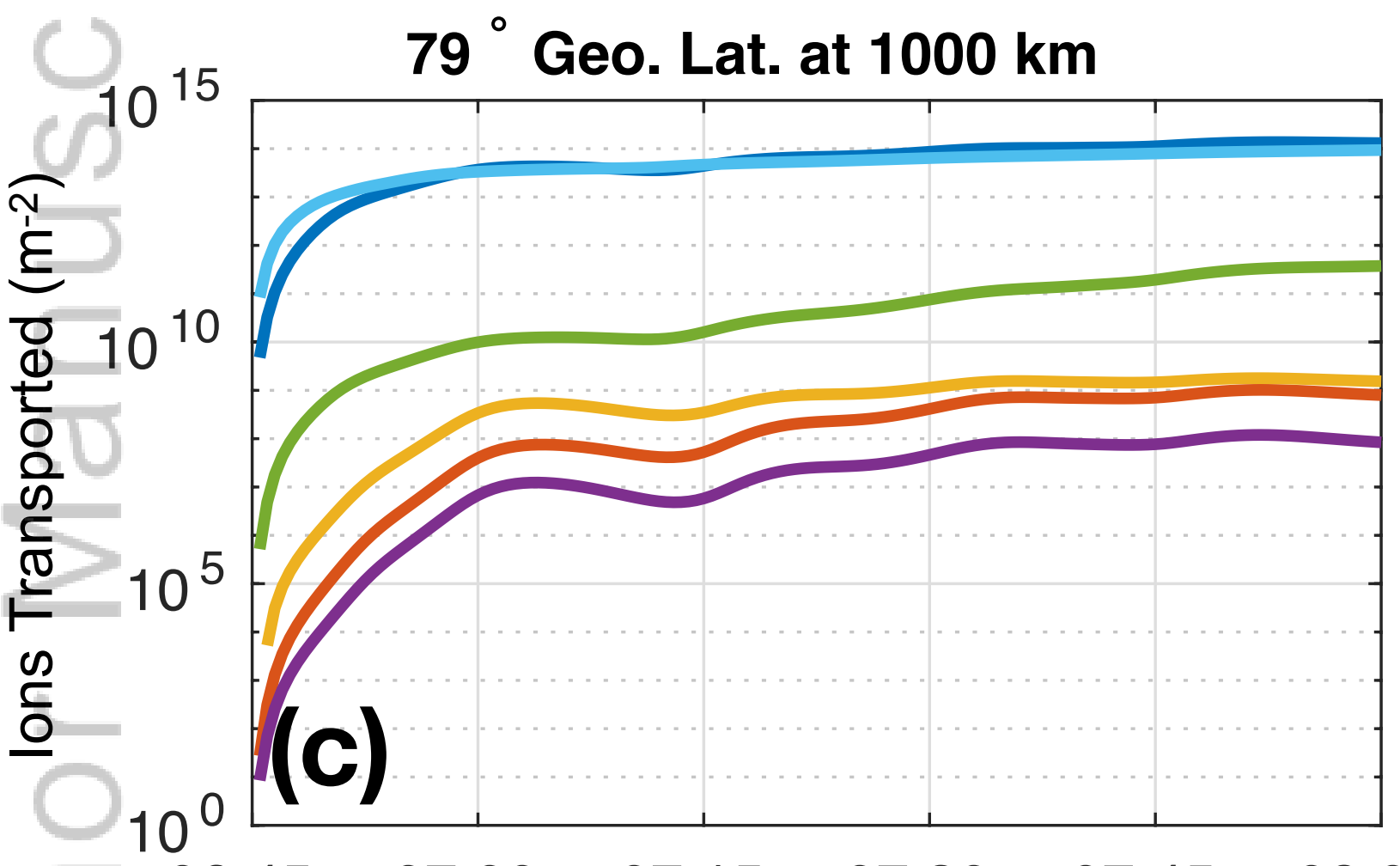

$\begin{array}{llllll}06: 45 & 07: 00 & 07: 15 & 07: 30 & 07: 45 & 08: 00\end{array}$ Time (UT)

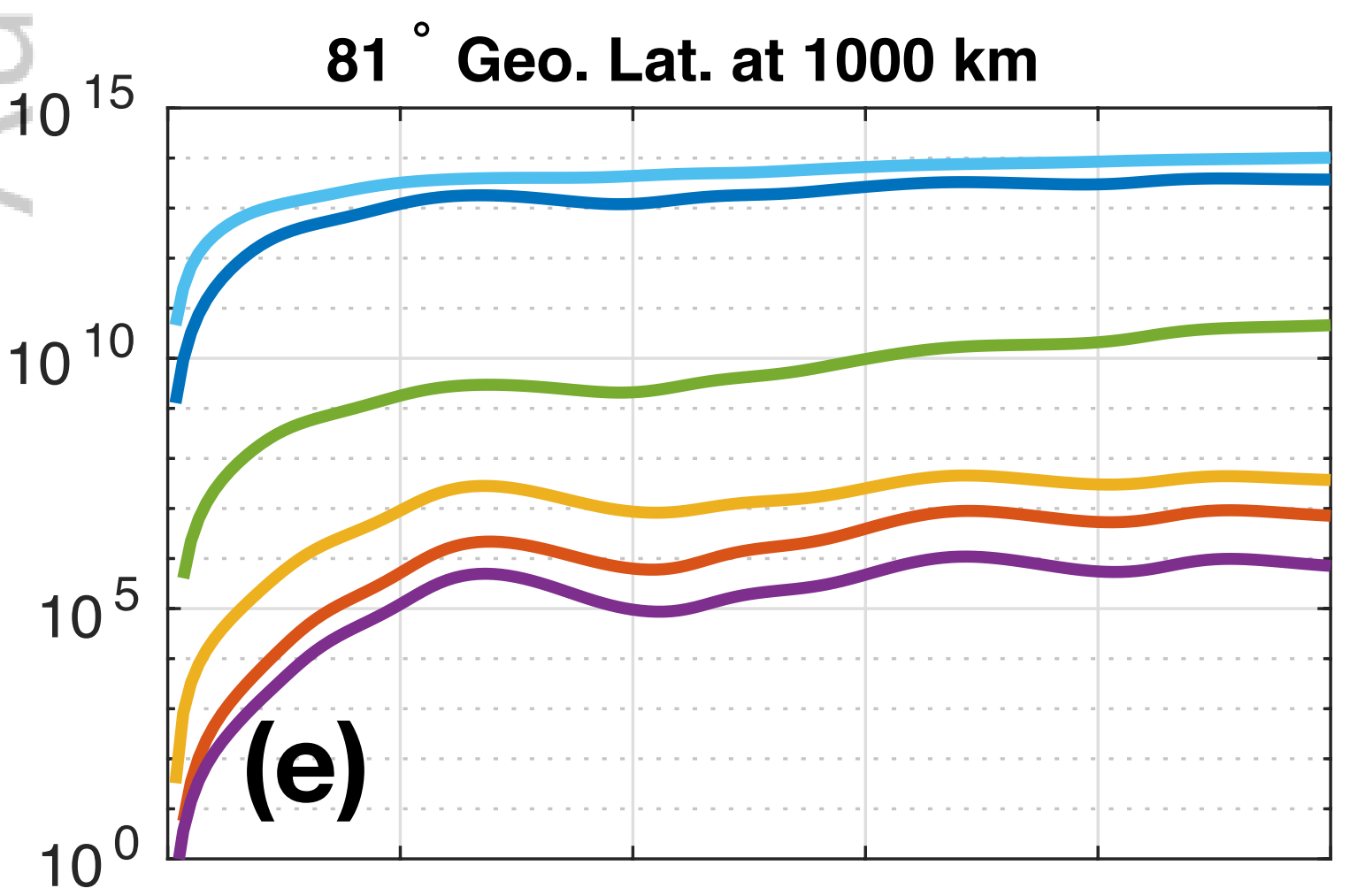

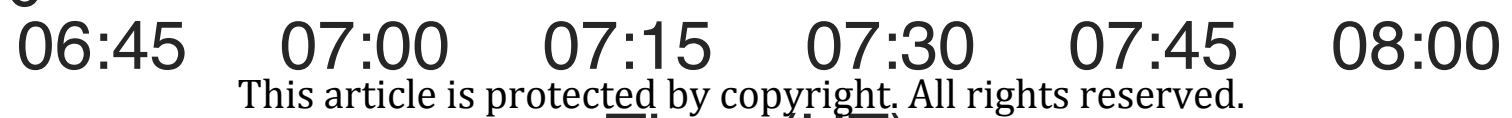
This article is protected by copyright. A

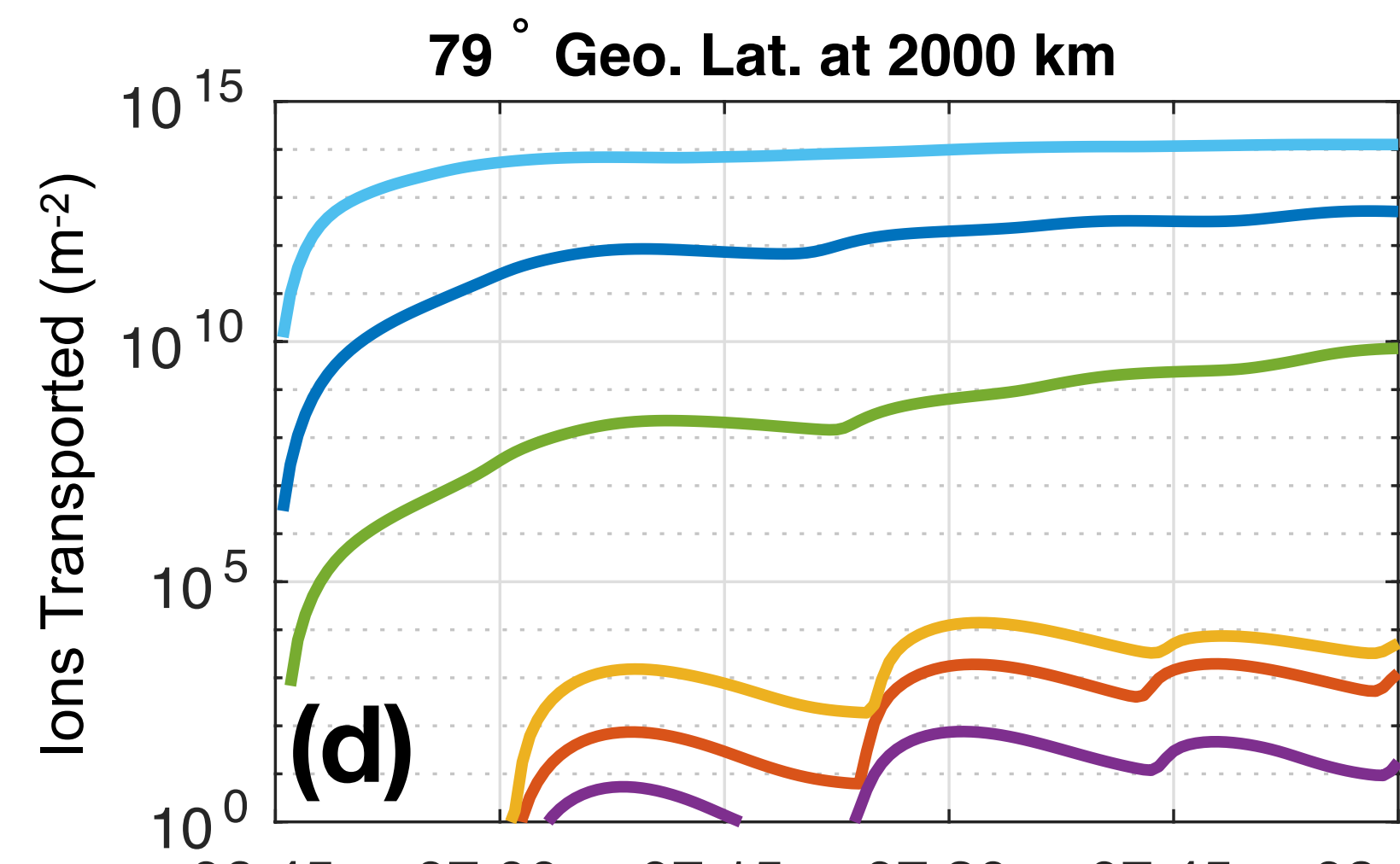

$\begin{array}{llllll}06: 45 & 07: 00 & 07: 15 & 07: 30 & 07: 45 & 08: 00\end{array}$ Time (UT)

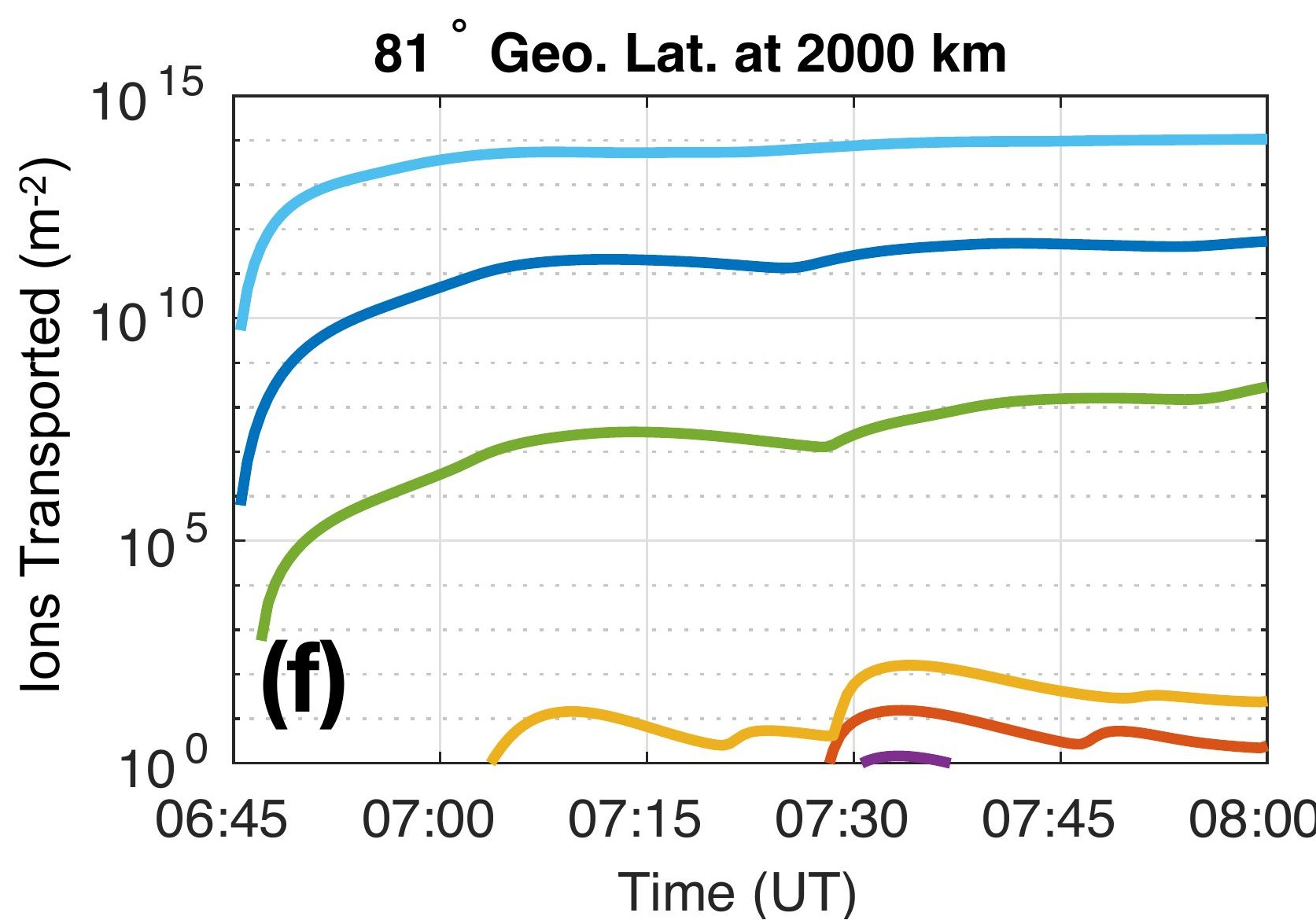




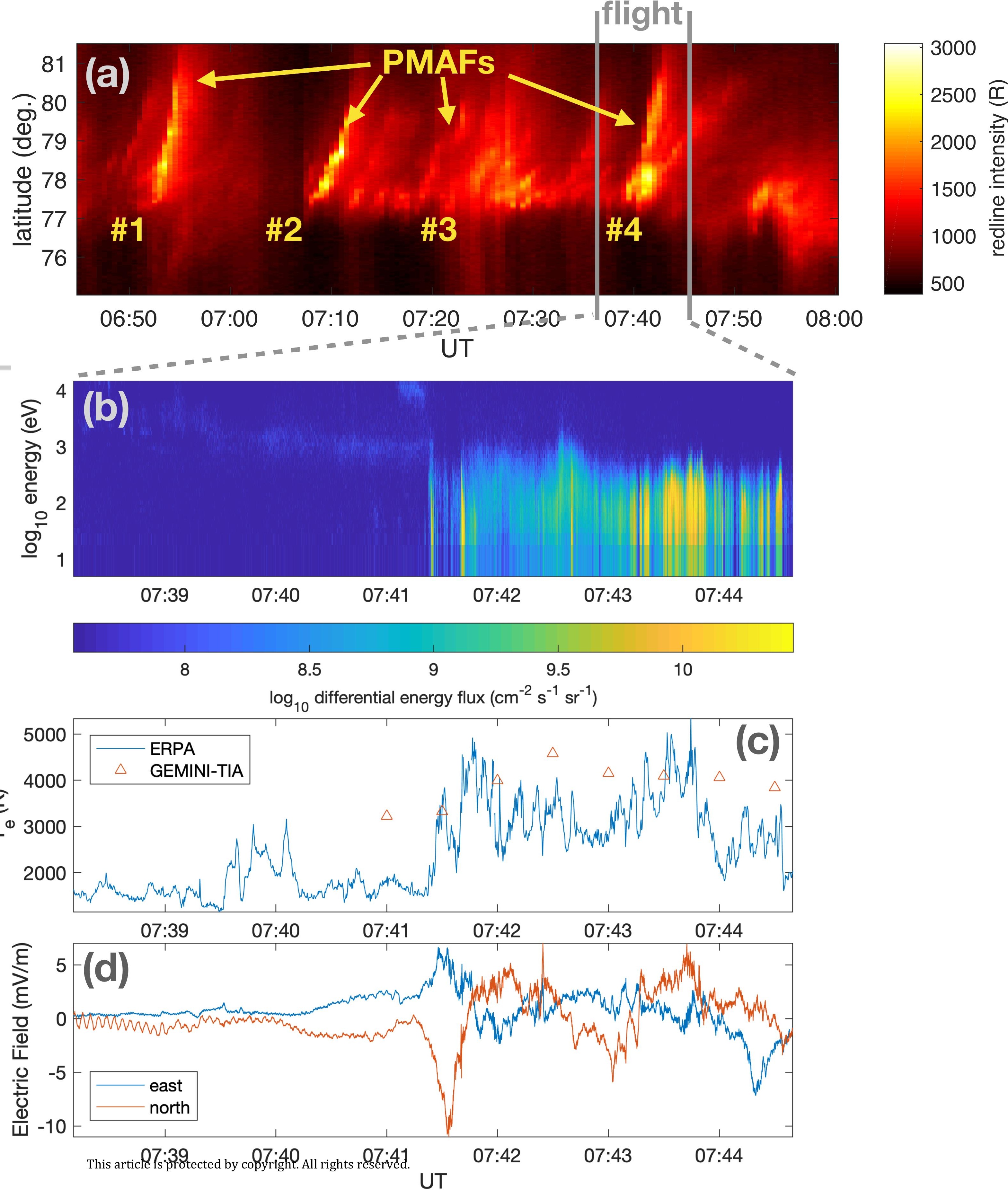



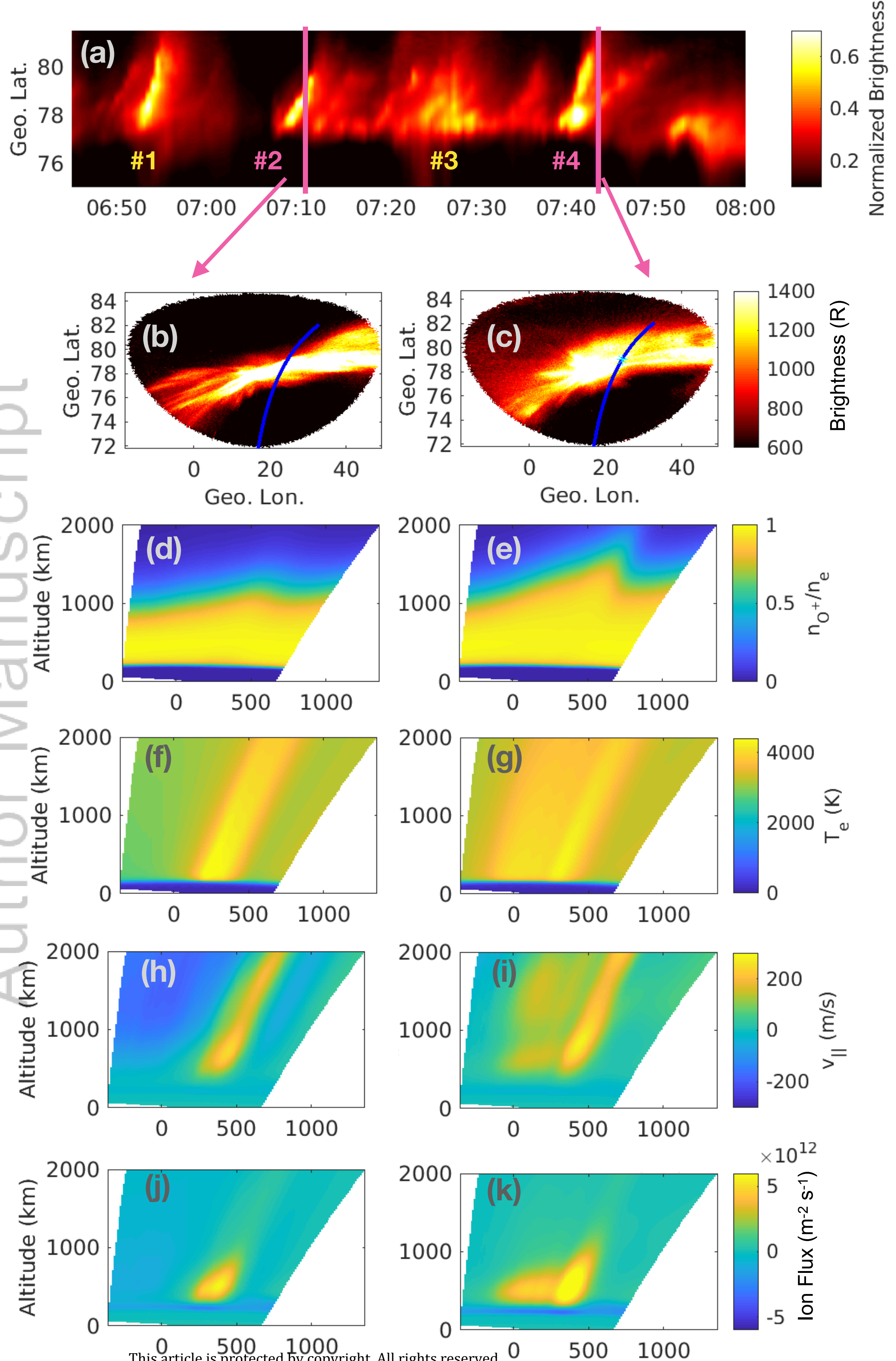

This article is protected by copyright. All rights reserved. $0 \quad 500 \quad 1000$ N-S Distance (km) N-S Distance $(\mathrm{km})$ 

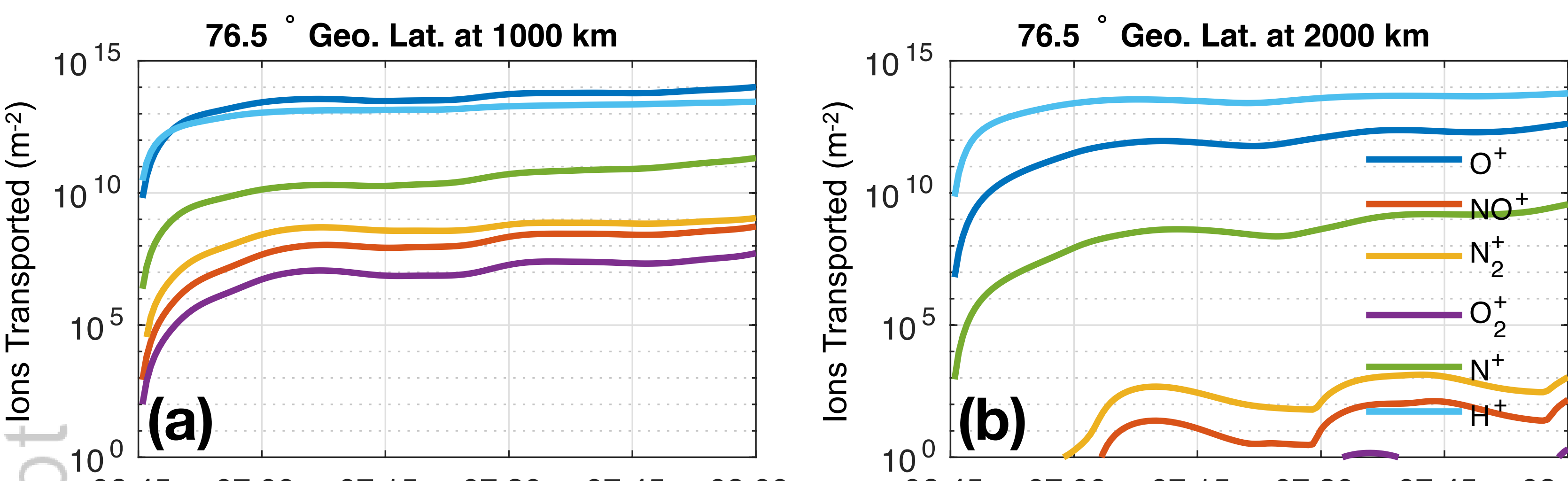

$\begin{array}{llllll}06: 45 & 07: 00 & 07: 15 & 07: 30 & 07: 45 & 08: 00\end{array}$ Time (UT)

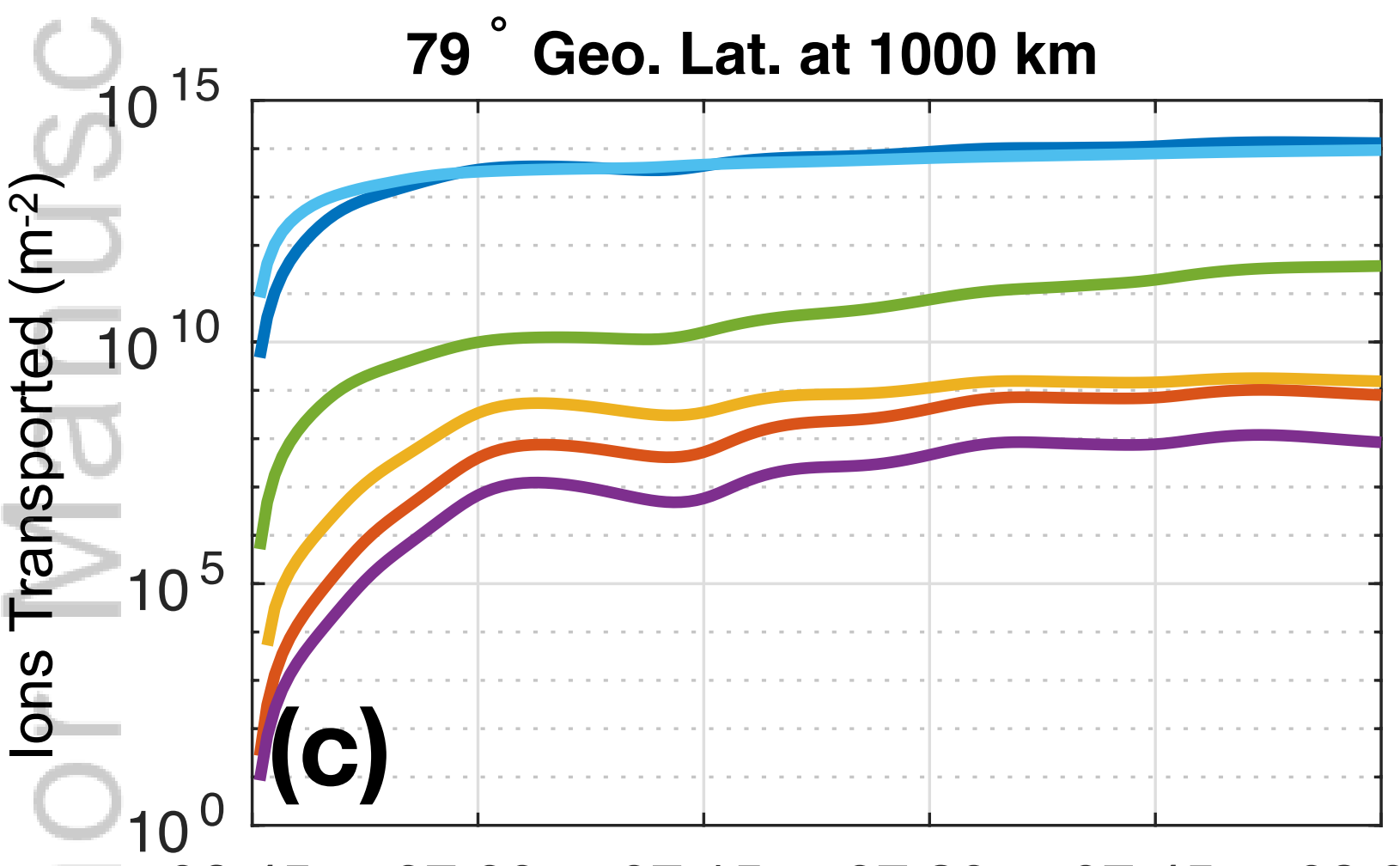

$\begin{array}{llllll}06: 45 & 07: 00 & 07: 15 & 07: 30 & 07: 45 & 08: 00\end{array}$ Time (UT)

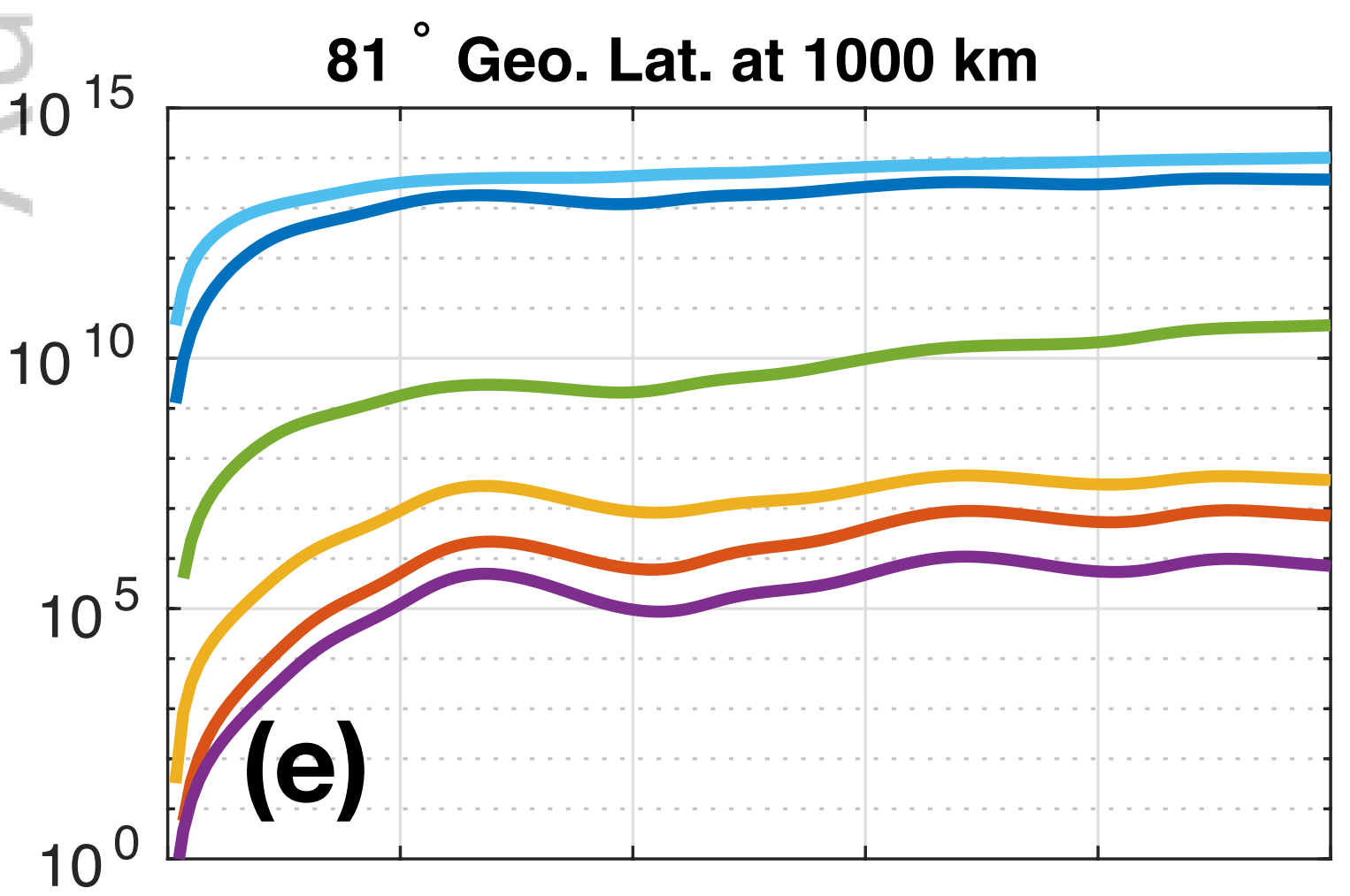

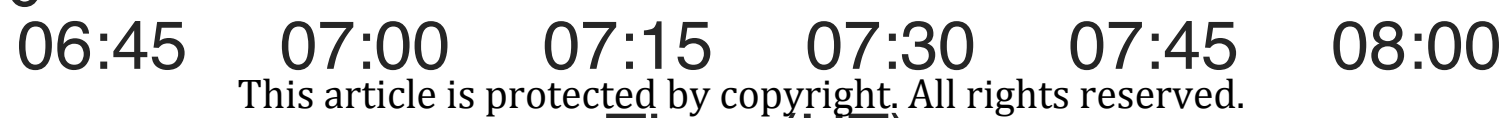
This article is protected by copyright. A

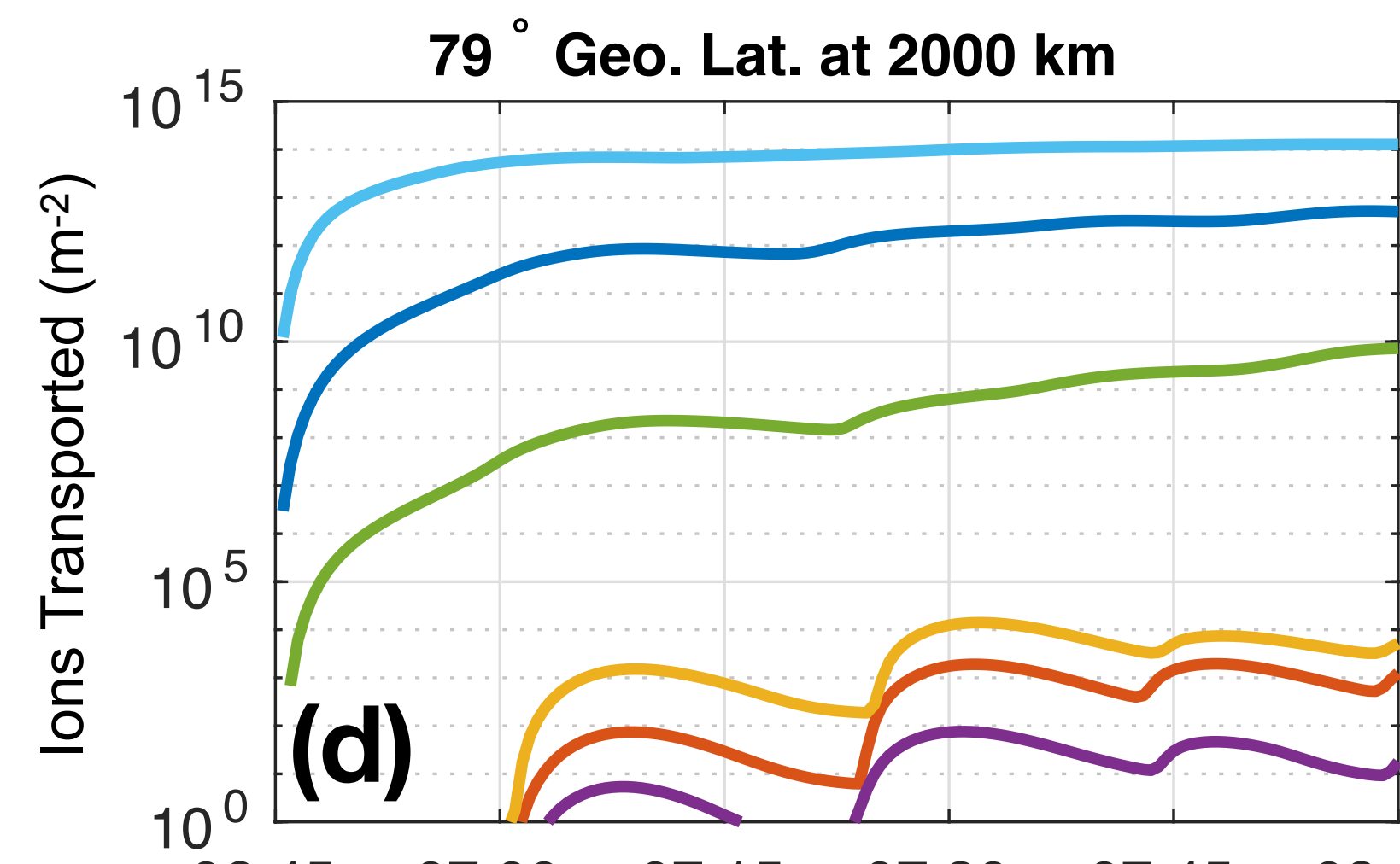

$\begin{array}{llllll}06: 45 & 07: 00 & 07: 15 & 07: 30 & 07: 45 & 08: 00\end{array}$ Time (UT)

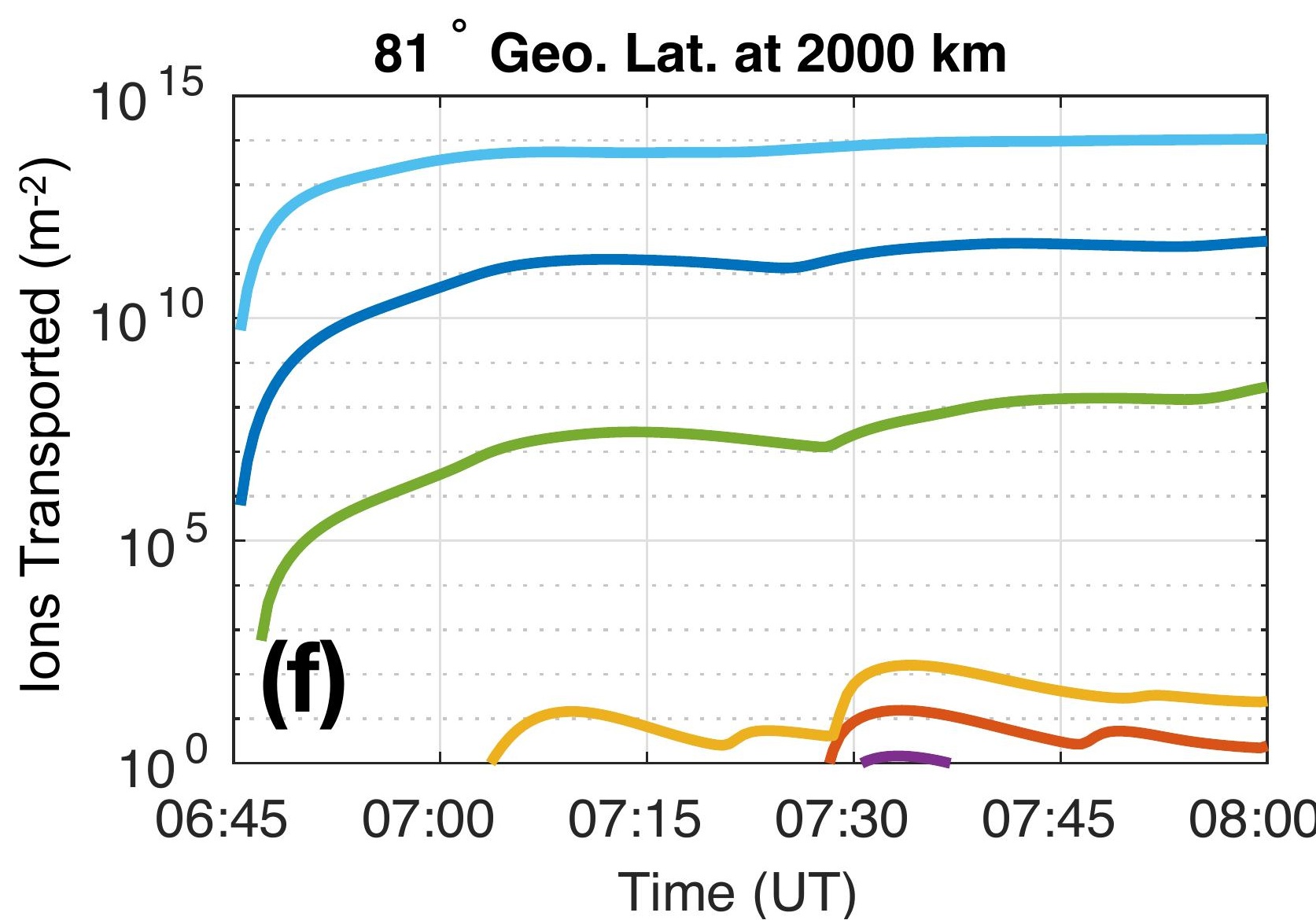

